\title{
Ruth Stronach, David Stronach, Alan Farahani, Alison Parson. "Mid-Parthian Pottery from Building V at Shahr-i Qumis"
}

\section{Barbara Kaim}

\section{(2) OpenEdition}

Journals

Édition électronique

URL : https://journals.openedition.org/abstractairanica/51827

DOI : 10.4000/abstractairanica.51827

ISSN : 1961-960X

Éditeur :

CNRS (UMR 7528 Mondes iraniens et indiens), Éditions de l'IFRI

\section{Référence électronique}

Barbara Kaim, « Ruth Stronach, David Stronach, Alan Farahani, Alison Parson. "Mid-Parthian Pottery from Building V at Shahr-i Qumis" », Abstracta Iranica [En ligne], Volume 42-43 | 2021, document 7, mis en ligne le 30 décembre 2020, consulté le 12 décembre 2022. URL : http://journals.openedition.org/ abstractairanica/51827 ; DOI : https://doi.org/10.4000/abstractairanica.51827

Ce document a été généré automatiquement le 12 décembre 2022.

Tous droits réservés 


\title{
Ruth Stronach, David Stronach, Alan Farahani, Alison Parson. "Mid- Parthian Pottery from Building V at Shahr-i Qumis"
}

\author{
Barbara Kaim
}

\section{RÉFÉRENCE}

Ruth Stronach, David Stronach, Alan Farahani, Alison parson. "Mid-Parthian Pottery from Building V at Shahr-i Qumis”, Iran, 57(2), 2019, p. 185-234

1 Notre connaissance de la céramique de la période parthe dans le nord-est de l'Iran reste encore extrêmement lacunaire. C'est donc une satisfaction de voir une nouvelle publication du matériel obtenu lors des fouilles du "Building V", une imposante structure, autrefois à trois étages. Une présentation détaillée du matériel céramique est précédée d'une discussion du plan du Bâtiment $\mathrm{V}$ et suivie par l'analyse de la distribution de la céramique dans les pièces du bâtiment. La céramique de Shahr-i Qumis, datant de la période parthe moyenne, forme un ensemble assez unique par rapport à la plupart des poteries de cette période actuellement connues d'Iran, bien que, comme le montre les A., il existe quelques analogies évidentes avec la poterie d'autres sites dans le nord-est de l'Iran. 


\section{AUTEURS}

BARBARA KAIM

Université de Varsovie 